\title{
Moving to 3D: relationships between coral planar area, surface area and volume
}

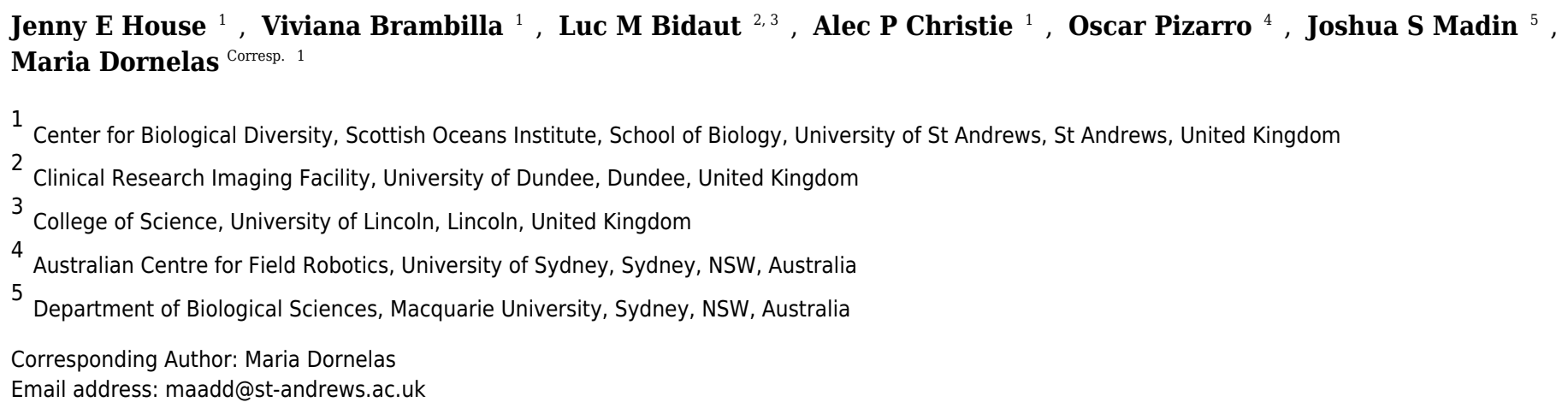

Coral reefs are a valuable and vulnerable marine ecosystem. The structure of coral reefs influences their health and ability to fulfill ecosystem functions and services. However, monitoring reef corals largely relies on 1D or 2D estimates of coral cover and abundance that overlook change in ecologically significant aspects of the reefs because they do not incorporate vertical or volumetric information. This study explores the relationship between 2D and 3D metrics of coral size. We show that surface area and volume scale consistently with planar area, albeit with morphotype specific conversion parameters. We use a photogrammetric approach using open-source software to estimate the ability of photogrammetry to provide measurement estimates of corals in 3D. Technological developments have made photogrammetry a valid and practical technique for studying coral reefs. We anticipate that these techniques for moving coral research from 2D into 3D will facilitate answering ecological questions by incorporating the 3rd dimension into monitoring. 


\section{Moving to 3D: relationships between coral planar area, \\ 2 surface area and volume}

3

4 Jenny E House ${ }^{1}$, Viviana Brambilla ${ }^{1}$, Luc M Bidaut ${ }^{2}$, Alec P. Christie ${ }^{1}$, Oscar Pizarro ${ }^{3}$, Joshua S. Madin ${ }^{4}$,

5 Maria Dornelas ${ }^{1}$

$6{ }^{1}$ Centre for Biological Diversity and Scottish Oceans Institute, School of Biology, University of St

7 Andrews, St Andrews, United Kingdom

$8 \quad{ }^{2}$ Clinical Research Imaging Facility, University of Dundee, Dundee, United Kingdom

9 College of Science, University of Lincoln, Lincoln, United Kingdom

10

11

12

13 Corresponding Author:

14 Maria Dornelas ${ }^{1}$

15 Dyers Brae, Centre for Biological Diversity, University of St Andrews, St Andrews, Fife, KY16 9TH, UK

16 Email address: maadd@st-andrews.ac.uk

17

18 Abstract

19 Coral reefs are a valuable and vulnerable marine ecosystem. The structure of coral reefs 20 influences their health and ability to fulfill ecosystem functions and services. However, 21 monitoring reef corals largely relies on 1D or 2D estimates of coral cover and abundance that 22 overlook change in biologically significant aspects of the reefs because they do not incorporate 23 vertical or volumetric information. This study explores the relationship between 2D and 3D 24 metrics of coral size. We show that surface area and volume scale consistently with planar area, 25 albeit with morphotype (or "growth form") specific conversion parameters. We use a 26 photogrammetric approach using open-source software to estimate the ability of photogrammetry 
27 to provide measurement estimates of corals in 3D. Technological developments have made 28 photogrammetry a valid and practical technique for studying coral reefs. We anticipate that these 29 techniques for moving coral research from 2D into 3D will facilitate answering ecological questions by incorporating the third dimension into monitoring.

Surface area and volume are 3D metrics particularly relevant for estimating the ecosystem services and functions performed by corals. Specifically, these two variables are critical for corals' reef building capability, which modulates many coral reef ecosystem services (Moberg \& Folke, 1999), such as effective coastal defences (Ferrario et al., 2014) and biodiversity support (Graham et al., 2006). As such, coral volume, which is related to metrics such as biomass, growth rate and production of carbonate (Cocito et al., 2003), is a trait of primary interest for monitoring purposes. The importance of quantifying the reef in $3 \mathrm{D}$ also relates to the overall structure of the reef. In fact, the loss of this complexity is a major consequence of disturbance that leads to the degradation of biogenic habitats (Airoldi, Balata \& Beck, 2008). While structural complexity can be maintained also by dead corals in the short term, many other ecologically significant functions, such as water filtering capability and productivity, are related to coral living surface area (Cocito et al., 2003). Microscale rugosity of colony surfaces facilitates larval recruitment (Hata el al., 2017), the continuous deposition of calcium carbonate ensures stability to the colonies structures and the predominance of living surface area in the 57 
58 The proportion of live coral cover on a reef is probably the most widely used metric of reef 59 health (Leujak \& Ormond 2007). A variety of techniques are used for estimating coral cover 60 (Loya 1972, Hill \& Wilkinson, 2004; Leujak \& Ormond, 2007; Vroom, 2010), most of which 61 focus on 2D (planar) measurements of colony size or coral cover (Gardner et al., 2003; Bruno \& 62 Selig, 2007; Sweatman et al., 2011). The ubiquity of 2D representations of coral reefs enables 63 standardization between and within different monitoring programs, allows them to be carried out 64 on a range of spatial scales, and facilitates the fast collection of estimates of abundance and 65 cover ( Shuman \& Ambrose, 2003; Hill \& Wilkinson, 2004; Booth et al., 2008). However, there 66 is increasing recognition of the need to develop better techniques for measuring coral colonies 67 and reefs in 3D to account for different morphologies and complexity of coral colonies (Burns et 68 al., 2015a; Burns et al., 2015b; Goatley \& Bellwood, 2011; Courtney et al., 2007). For instance, 69 overlooking the vertical aspect of coral reefs results in an inability to fully assess their structural complexity and measure ecologically significant changes (Goatley \& Bellwood, 2011). In fact, coral morphotypes (also known as "growth forms") differ in their demographic rates and play 73 (Madin \& Connolly, 2006) in their mortality schedule (Madin et al., 2014), fecundity 74 (Álvarez - Noriega et al., 2016) and growth rates (Dornelas et al., 2017), and affect habitat complexity at different scales (Richardson et al., 2017). Moreover, changes in the relative abundance of different morphotypes of corals may influence the provision of ecosystem services and biodiversity (Alvarez-Filip et al., 2011; Burns et al., 2015b). Using 3D approaches to better understand the structure and function of different coral morphotypes, as well as their vulnerability to disturbance, is an important step towards elucidating the goods and services that reefs provide.

81

In comparison to $2 \mathrm{D}$ techniques, methods that collect $3 \mathrm{D}$ data in the field are costly, time consuming and difficult to carry out (Laforsch et al., 2008; Naumann et al., 2009; Goatley and Bellwood, 2011), in addition to often being invasive or imprecise (Naumann et al., 2009). To overcome these problems, Structure-from-Motion (SfM) photogrammetric approaches became very useful in underwater settings since they permit the construction of three-dimensional digital models of objects beginning with a sequence of pictures of the object itself. These techniques no longer require specification of known 3D locations prior to calculating camera positions 
89 (Westoby et al., 2012) and the ability to automatically match corresponding points across 90 images. The precision and accuracy of this method has been demonstrated at different scales 91 (Figueira et al., 2015; Gutierrez-Heredia et al., 2016; Storlazzi et al., 2016).

92

93 A growing number of studies present 3D reconstructions of coral reefs using SfM through 94 proprietary software (Burns et al., 2015; Burns et al., 2016; Raoult at al., 2016; Raoult et al., 95 2017) or their own algorithms (Friedman et al. 2012; Ferrari et al., 2015; Pizarro et al., 2017). 96 However, open access software is now available and being used among coral reef scientists (Lavi 97 et al., 2015; Figueira et al., 2015; Gutierrez-Heredia et al., 2016; Agudo-Adriani et al., 2016), 98 making SfM more accessible to a broad community. Therefore, calls for a switch towards 3D 99 monitoring programs are gaining traction (Raoult et al., 2016; Pizarro et al., 2017). Assessments 100 of measurement error associated to this technique are a fundamental part of the transition 101 towards monitoring reefs in 3D (Bryson et al 2017). Moreover, the consequences of this shift for 102 loss of comparability with past monitoring, which largely involves planar imagery need to be 103 assessed.

104

105 This paper addresses two aspects of moving from measuring corals in 2D to 3D. First, we ask 106 whether we can predict 3D metrics of coral size from 2D metrics. We hypothesize that coral 107 morphotypes differ in their scaling relationships between 2D and 3D metrics. The second aim of 108 our study is to measure corals in 3D directly. We determine whether SfM provides accurate 109 estimates of the surface area and volume of coral skeletons, and ask whether there are biases in 110 this technique associated to different morphotypes. If the first assumption is met and SfM is 111 demonstrated reliable, then a methodological shift in monitoring towards measuring traits in the 112 three dimensions is possible, without losing the possibility to compare the results with previous 113 data. The methodology developed allows including 3D metrics into coral reef monitoring, 114 improving how we quantify change in coral reefs.

116 Methods

117 In order to capture 2D and 3D data, we used three methods for measuring coral skeletons, as 118 outlined in Figure 1. First, we measured colony planar total surface area (PL TSA) from birds119 eye-view photographs of the colonies with a scale. Computed tomography (CT) scans and 
120 photogrammetry $(\mathrm{PH})$ were used on the same specimens to produce information about 3D

121 metrics, namely colony total surface area and volume (hereafter abbreviated to CT TSA, CT Vol,

122 PH TSA and PH Vol respectively). In order to explore the most biologically useful information,

123 the surface area of the colony that had been covered in corallites was also measured. This "live"

124 surface area was produced from the results of all three methods; planar photography (PL LSA),

125 photogrammetry (PH LSA) and CT scanning (CT LSA). Due to its high resolution, accuracy and

126 inherent 3D nature, the data collected using CT scans was used as a baseline (Veal et al., 2010)

127 with which to compare the other two methods. Using this suite of techniques enabled us to 128 examine the relationship between 2D and 3D metrics, as well as address some of the difficulties 129 with collecting $3 \mathrm{D}$ data.

130

131

132

\begin{tabular}{|c|c|c|c|}
\hline \multirow{3}{*}{$\begin{array}{c}\text { Specimen } \\
\text { selection } \\
22 \text { specimens } \\
7 \text { morphotypes }\end{array}$} & \multicolumn{2}{|c|}{ 2D: Planar photography } & \multirow[b]{2}{*}{$\rightarrow \mid \begin{array}{c}\text { Calculate outlined } \\
\text { area to measure } \\
\text { Planar TSA \& LSA }\end{array}$} \\
\hline & $\begin{array}{l}\text { Birds-eye-view } \\
\text { photography } x 3\end{array}$ & $\begin{array}{l}\text { Outline colony (total } \\
\text { \& live only) and } \\
\text { mark scale bar }\end{array}$ & \\
\hline & & \multicolumn{2}{|c|}{ Software used: ImageJ \& R } \\
\hline & \multicolumn{3}{|c|}{$\downarrow$} \\
\hline \multicolumn{4}{|l|}{ 3D: Photogrammetry } \\
\hline $\begin{array}{l}\text { Take overlapping } \\
\text { photographs in } \\
\text { hemispherical } \\
\text { formation } \\
\text { of specimen \& }\end{array}$ & $\begin{array}{c}\text { Create sparse } \\
\text { and dense point } \\
\text { clouds }\end{array}$ & $\begin{array}{l}\text { Create and scale } \\
\text { mesh. Trim to } \\
\text { produce a whole } \\
\text { colony mesh and a } \\
\text { version limited to }\end{array}$ & \multirow{3}{*}{\begin{tabular}{|c|} 
Measure: \\
Photogrammetry TSA \\
Photogrammetry LSA \\
Photogrammetry Vol \\
Meshlab \& Blender \\
(NeuroMorph tool)
\end{tabular}} \\
\hline scale bars & & "live" areas & \\
\hline Software used: & Visual SFM & Meshlab & \\
\hline \multicolumn{4}{|c|}{$\downarrow$} \\
\hline 3D: CT scanning & & & \multirow{3}{*}{$\begin{array}{l}\text { Statistical analysis } \\
\begin{array}{c}\text { Comparison of } \\
\text { different methods }\end{array} \\
\begin{array}{c}\text { Predicting 3D } \\
\text { from 2D data }\end{array}\end{array}$} \\
\hline $\begin{array}{c}\text { CT scans: } \\
0.6 \mathrm{~mm} \text { slice width, } \\
0.6 \mathrm{~mm} \text { increment, } \\
0.5 \text { pitch }\end{array}$ & $\begin{array}{l}\text { Reconstruct with } \\
\text { H40 kernel filter } \\
\text { and trim mesh to } \\
\text { give "live" version }\end{array}$ & $\begin{array}{l}\text { Measure: } \\
\text { CT TSA } \\
\text { CT LSA } \\
\text { CT Vol }\end{array}$ & \\
\hline & \multicolumn{2}{|c|}{ Software used: Meshlab \& Blender } & \\
\hline
\end{tabular}

133 Figure 1: The complete process used to measure TSA, LSA and volume in 2D and

$1343 \mathrm{D}$ for each specimen, including the measurement techniques and software used. 


\section{Specimen selection}

138 We selected coral skeletons from the collection at the Bell Pettigrew Museum, University of St

139 Andrews with replicate specimens across different morphotypes and sizes. Each specimen was

140 identified to species, and their morphotype was classified as branching, encrusting or massive.

141 The resulting selection of coral skeletons includes 22 specimens described in Table S2.

142

143 Photography and planar surface measurement

144 Coral specimens were photographed in air from above with a $10 \mathrm{~cm} \mathrm{x} 10 \mathrm{~cm}$ chessboard-style 145 calibration pattern using a digital camera (Nikon D40, 18-55mm lens) as seen in Figure 2a. The 146 specimens were positioned on the plane in such a way as to replicate their natural orientation on 147 the reef as much as possible. Each coral skeleton was photographed three times to account for 148 and minimize the effect of measurement error. The specimens were repositioned for each 149 photograph so as to minimize bias resulting from a particular position or camera angle.

150

151 All of the photos were then processed using the image analysis software ImageJ (Rasband, 152 2014). For each step the image was zoomed in in order to have the entire colony and scale 153 completely in view and as big as possible. A graphics tablet (medium Intuos, Wacom) was used 154 to draw the outline of the whole coral colony and the areas that consisted of corallites. These 155 contours were saved as a series of XY coordinates. The corners of the calibration pattern were 156 also marked and saved as coordinates, in order to convert the pixel measurements into length $157(\mathrm{~cm})$. After the necessary information had been extracted from the images and converted into XY 158 coordinates, R (R Core Team, 2013) was used to calculate PL TSA and PL LSA from the 159 relevant outlines (in square centimetres), using methodology and code from Madin et al. (2014). 
161
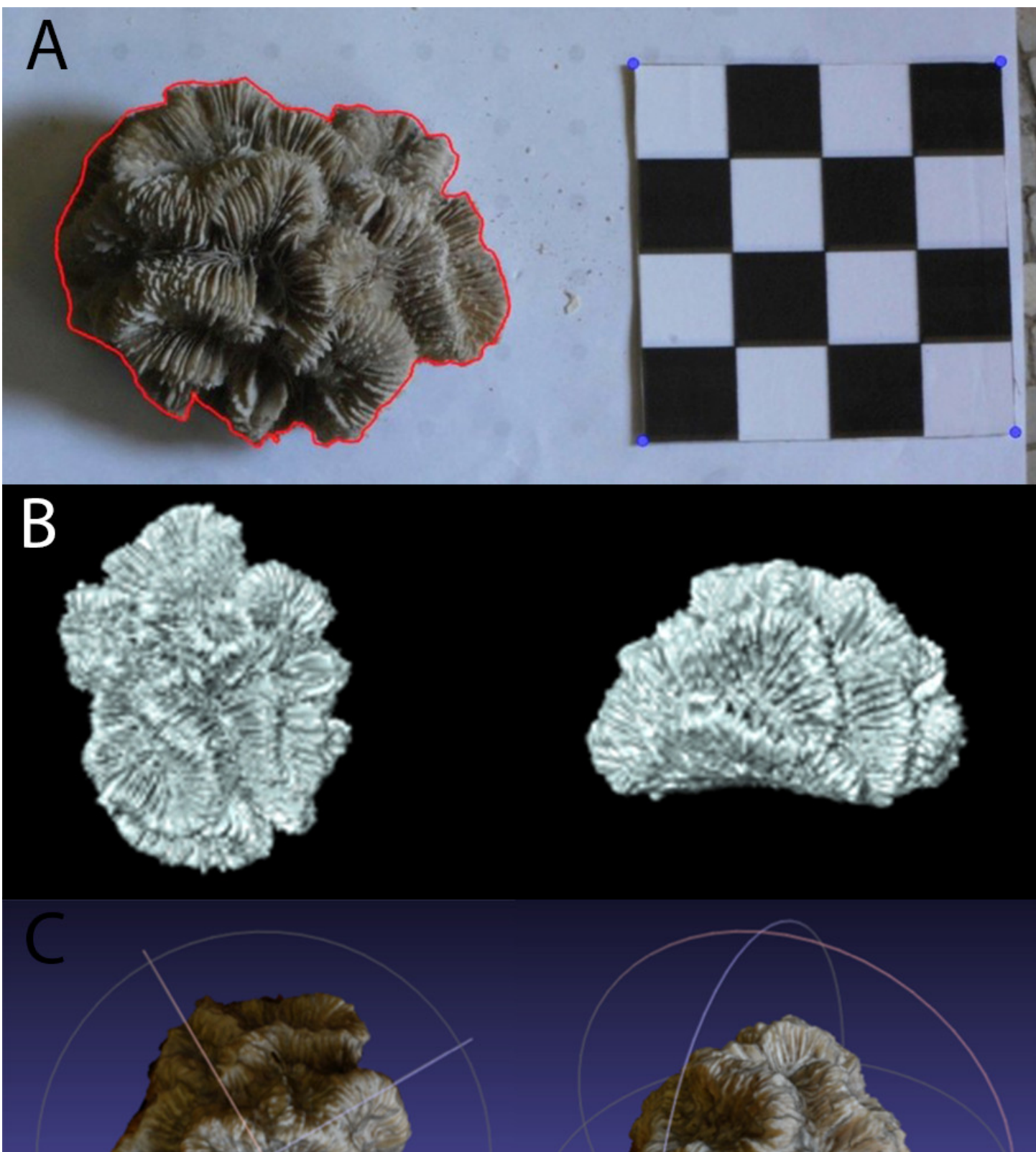

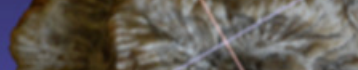
E

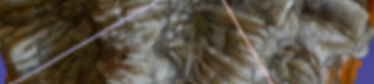

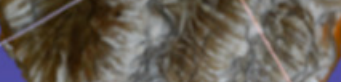

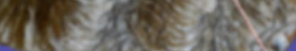

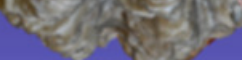

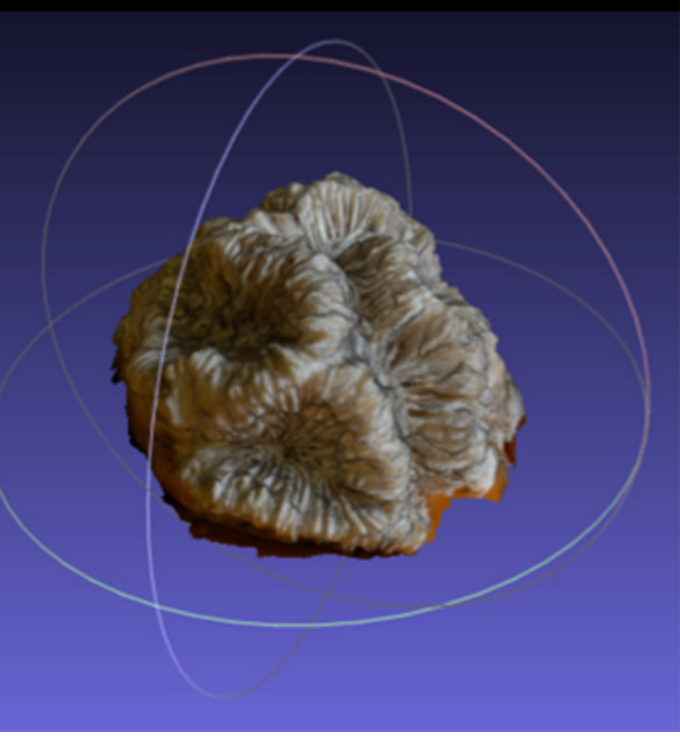


163 Figure 2: Example of A) planar photography of a coral colony having been

164 outlined and scaled using Image J and R, B) the surface generated using CT 165 scanning, and C) the equivalent surface generated using SfM photogrammetry.

166

167

168 Structure from motion

169 Photographs were taken using the same digital camera and a static off-camera flash set-up as for 170 the planar photography. The specimens were placed on a table with four $10 \mathrm{~cm}$ scale bars 171 positioned in a square on the surface around them. Photographs were taken with the camera 172 positioned at various locations on a virtual hemispherical dome above the specimen, as 173 illustrated in Figure 3. This created a hemisphere-like spread of images of the specimen from 174 various viewpoints. Significant overlap between images is needed in order to automatically 175 identify shared points that can then be reconstructed as 3D coordinates. The number of views 176 varied from 39 to 164 based on the size and complexity of the specimen. Specimens with 177 occluding structures require the highest number of photographs in order to produce the necessary 178 coverage. Distortions were not corrected.

179 

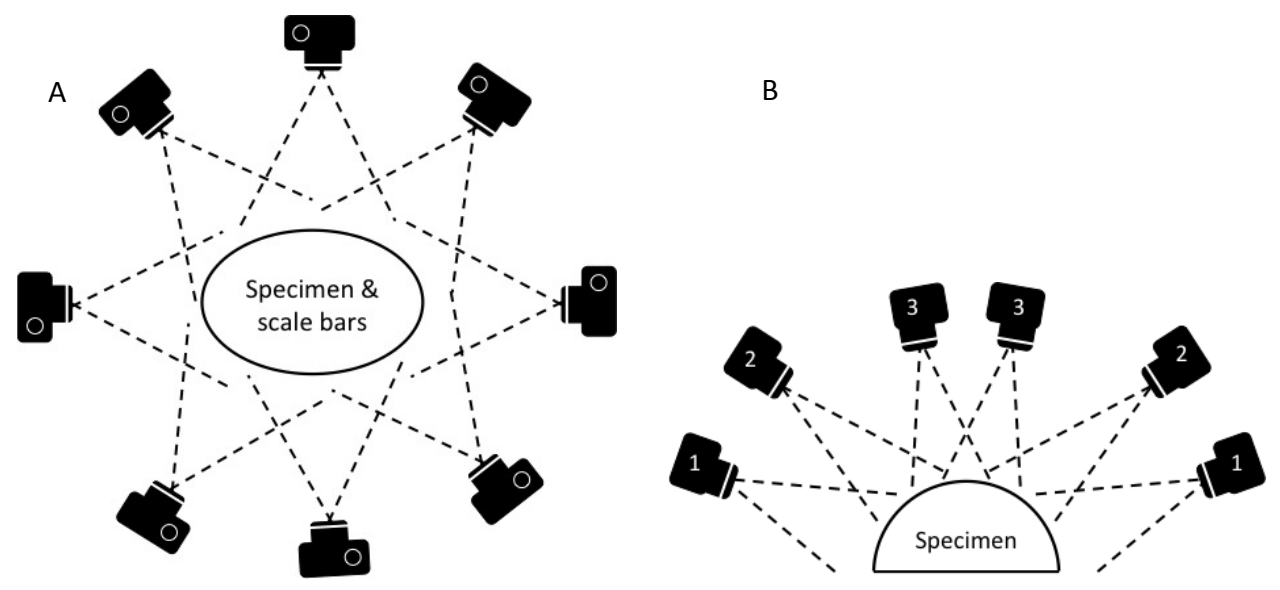

180

181

182 Figure 3: Schematic of camera positions used to produce images for SfM 183 photogrammetry. In order to create a hemispherical spread of images, three rings

184 of photographs at different heights (A) were constructed using overlapping images 185 (B).

186 Digital model construction was done on an Intel Quad Core $3.40 \mathrm{GHz}$ desktop computer with 16 187 GB RAM under Windows 7 Professional. The open-source software package Visual SFM (Wu 188 2007; Wu 2011; Wu et al., 2011) was used to create a point mesh from the overlapping images 189 by determining camera positions and generating a sparse point cloud. This was then followed by 190 dense reconstruction using an additional package for Clustering views for Multi-View Stereo 191 (CMVS) and Patch-based Multi-View Stereo (PMVS v2) (Furukawa et al., 2010; Furukawa \& 192 Ponce, 2010).

193

194 The dense point cloud was then imported into MeshLab (Cignoni, Corsini and Ranzuglia, 2008) 195 and spurious points were removed. A surface layer was created from the point mesh using 196 Poisson Surface Reconstruction. The scale bars were used to determine the coefficient needed to 
197 convert the mesh from pixels to absolute units, in this case millimetres. The model was then 198 trimmed to remove the table and non-coral objects, as shown in Figure 2c. The volume and 199 surface area for these meshes were calculated using Blender (www.blender.org) with the 200 NeuroMorph plug-in (Jorstad et al., 2014), thus producing PH TSA and PH Vol. To include PH 201 LSAs, that are ecologically more meaningful than the specimen's entire surface area, the surface 202 portions corresponding to not living corallites were selected and removed in MeshLab. To reduce 203 the influence of any measurement errors, three models were produced for each specimen using 204 different sets of images.

205

206

207

\section{Computed tomography and 3D surface measurement}

208

The coral specimens were scanned in air using a medical CT scanner, Siemens Biograph mCT128. The protocol was based upon that of Naumann et al (2009). The images were acquired at $0.6 \mathrm{~mm}$ slice width, $0.6 \mathrm{~mm}$ increments and 0.5 pitch. Xray tube voltage was $120 \mathrm{kV}$ with effective mAs of 341 (automatically varied) and a field of view that was adapted to the size of each specimen. Three back-projection reconstructions were then produced for each colony from the spiral mode acquisition dataset, with sharp, medium and smooth kernel filters (H30, H40 \& $\mathrm{H} 50$ ). Of these, the $\mathrm{H} 40$ reconstruction was selected for subsequent calculations because it gave the best compromise between high spatial resolution and low image noise. Using the corresponding 3D reconstructions of the coral colonies (example shown in Figure 2b), measurements of CT TSA and CT Vol were generated in square and cubic millimeters, respectively. As with the meshes produced through SfM, Meshlab was used to trim away areas without corallites, and the CT LSA was then measured in Blender through the NeuroMorph

Statistical analysis

222 CT metrics of size are used as response variables in our models since scanning can detect surface 223 rugosity at a scale as small as $1000 \mu \mathrm{m}^{2}$ (Veal et al. 2010) and provide the most accurate 224 estimates of corals 3D features (Laforsch et al., 2008; Naumann et al., 2009; Veal et al. 2010). 225 To address the first aim of testing whether 3D metrics can be inferred from 2D metrics of size, 226 we fitted Ordinary Least Squares linear models predicting CT TSA and CT Vol from PL TSA 227 and morphotype, and CT LSA from PL LSA and morphotype. Models with and without 
228 morphotype were compared using the Akaike Information Criterion (AIC) to assess whether 229 differences in scaling among morphotypes affect the compromise between goodness of fit and 230 model complexity. In addition, Adjusted $\mathrm{R}^{2}$ 's were used to assess the predictive ability of the 231 different models.

232

233 Our second aim was to assess the ability of photogrammetry to estimate 3D metrics of coral size. 234 As per the previous aim, we fitted Ordinary Least Squares linear models predicting CT TSA, CT 235 LSA, and CT Vol from PH TSA, PH LSA, or PH Vol and morphotype. We performed model 236 selection as above to investigate morphotype associated bias in the estimates. Finally, we 237 compared Adjusted $\mathrm{R}^{2}$ 's of these models with those of a model with slope 1 and intercept 0 .

These models used single measurements for CT TSA and CT Vol, but mean values were used for each specimen's PL TSA/LSA, PH TSA/LSA and PH Vol. All variables were log transformed to improve symmetry in the distribution of the residuals and to linearize the relationship between area $\left(\mathrm{mm}^{2}\right)$ and volume $\left(\mathrm{mm}^{3}\right)$. Statistical analysis was carried out in $R$ (R Core Team, 2013).

243

\section{Results}

245 Colony planar area (PL TSA and PL LSA) can be used to infer accurate estimates of surface area 246 and volume of the CT scanner models (CT TSA, CT LSA and CT Vol). As expected, 3D surface 247 area is higher than 2D area, however the former scales tightly with the latter (Figure 4 A, B). 248 Also, 3D volume is lower than the volume of a cube with a similar area, but again the scaling 249 relationship is remarkably tight (Figure $4 \mathrm{C}$ ). The proportion of variance explained by the best 250 model for each of these variables ranges between 0.81 and 0.90 (Table 1). Model selection 251 suggests that morphotypes differ in their scaling relationship only for CT LSA (Figure 4, B, 252 Table 2). For both CT TSA and CT Vol the slope in the best model is constant across 253 morphotypes, although for CT Vol morphotypes differ in their intercept (Figure 4, Table 2). 

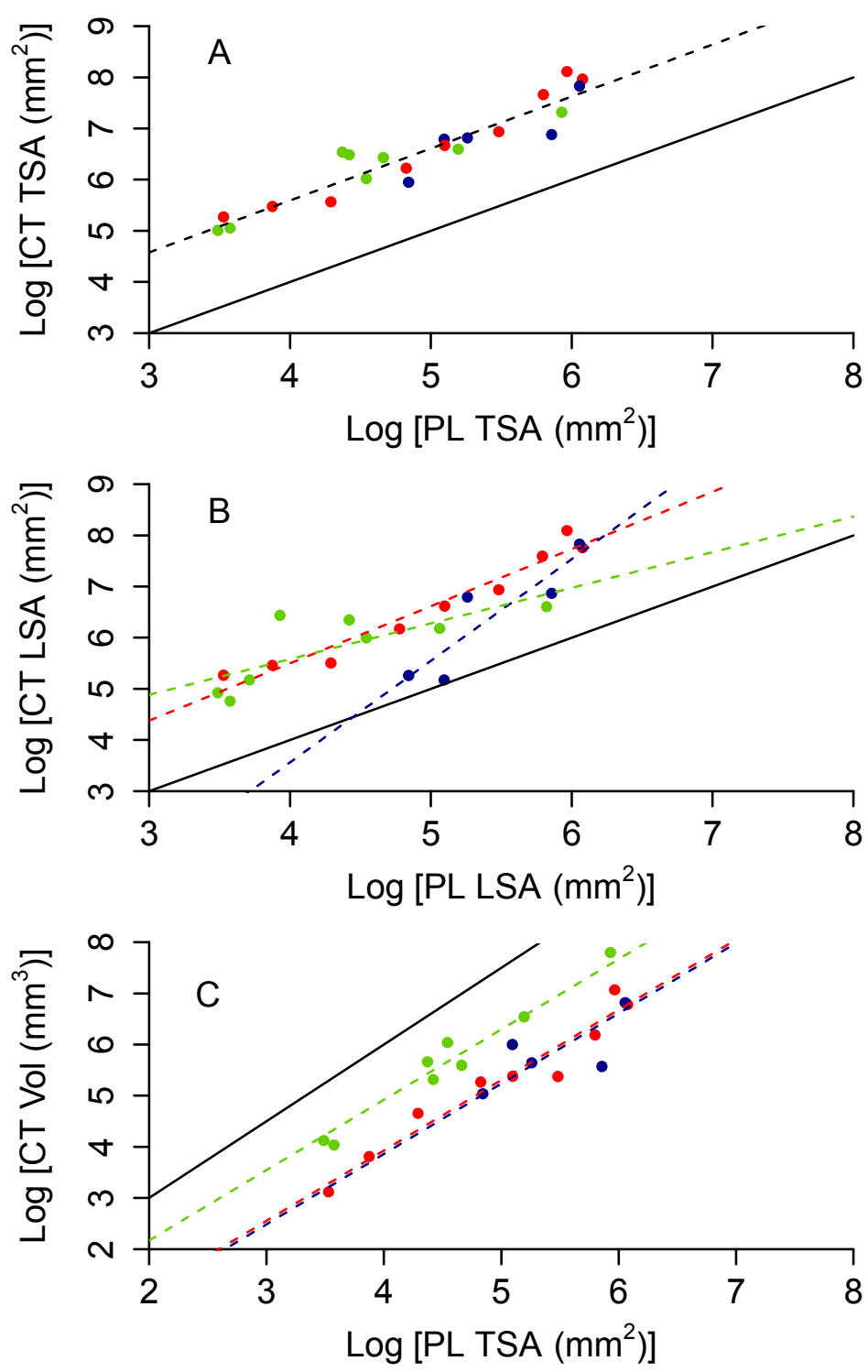

255 Figure 4. 3D metrics of size as a function of 2D metrics. Red circles represent 256 branching colonies, blue encrusting and green massive. The solid lines represent a 257 model where 3D metric is equal to the 2D metric (A, B) or the relationship predict 258 for a cube (C). Dashed lines represent predictions for the best model, with different 259 colours for different morphotypes as per the symbols when morphotypes differ in 260 parameter estimates. 
262

263 Table 1: Predictive accuracy of planar total or live surface area (PL TSA/LSA) 264 when used alone and with morphotype to estimate CT TSA, CT LSA, CT Vol, 265 respectively. Adjusted $\mathrm{R}^{2}$, p-value and Akaike's Information Criterion (AIC) are 266 given to 2 significant figures.

\begin{tabular}{|c|c|c|c|c|}
\hline Response & Predictor(s) & $\begin{array}{c}\text { Adjusted } \\
\mathbf{R}^{\mathbf{2}}\end{array}$ & $\mathbf{p}$ & AIC \\
\hline \multirow{3}{*}{ CT TSA } & PL TSA & 0.88 & $5.40 \times 10^{-11}$ & 15.03 \\
\hline & $\begin{array}{l}\text { PL TSA + } \\
\text { morphotype }\end{array}$ & 0.88 & $2.55 \times 10^{-8}$ & 16.01 \\
\hline & $\begin{array}{l}\text { PL TSA * } \\
\text { morphotype }\end{array}$ & 0.88 & $7.22 \times 10^{-8}$ & 18.07 \\
\hline \multirow{3}{*}{ CT LSA } & PL LSA & 0.70 & $3.65 \times 10^{-7}$ & 39.67 \\
\hline & $\begin{array}{l}\text { PL LSA + } \\
\text { morphotype }\end{array}$ & 0.745 & $3.55 \times 10^{-06}$ & 37.86 \\
\hline & $\begin{array}{l}\text { PL LSA * } \\
\text { morphotype }\end{array}$ & 0.81 & $3.31 \times 10^{-06}$ & 32.88 \\
\hline \multirow{3}{*}{ CT Vol } & PL TSA & 0.73 & $2.42 \times 10^{-07}$ & 42.85 \\
\hline & $\begin{array}{l}\text { PL TSA + } \\
\text { morphotype }\end{array}$ & 0.90 & $9.76 \times 10^{-10}$ & 23.14 \\
\hline & $\begin{array}{l}\text { PL TSA * } \\
\text { morphotype }\end{array}$ & 0.90 & $1.79 \times 10^{-8}$ & 23.67 \\
\hline
\end{tabular}

267 
270 Table 2: Parameter estimates for best models to predict CT TSA, CT LSA and CT 271 Vol from PL TSA or LSA to for coral colonies of a range of morphotypes. All 272 variables in the regression models were log transformed hence a general predictive 273 function is $C=e^{\alpha+\beta \ln (P)}$, where C is CT TSA, CT LSA or CT Vol and P is PL 274 TSA, or PL LSA as per Figure 1.

275

\begin{tabular}{|c|c|c|c|}
\hline Response & morphotype & $\alpha(\mathrm{CI})$ & B (CI) \\
\hline CT TSA & all & $\begin{array}{c}1.528(0.692 \text { to } \\
2.365)\end{array}$ & $\begin{array}{c}1.016(0.849 \text { to } \\
1.184)\end{array}$ \\
\hline \multirow{3}{*}{ CT LSA } & branching & $\begin{array}{c}1.024(-0.749 \text { to } \\
2.797)\end{array}$ & $\begin{array}{c}1.118(0.768 \text { to } \\
1.468)\end{array}$ \\
\hline & encrusting & $\begin{array}{c}-4.387(-10.597 \text { to }- \\
0.225)\end{array}$ & $\begin{array}{c}1.987(-0.093 \text { to } \\
1.830)\end{array}$ \\
\hline & massive & $\begin{array}{c}2.796(-0.812 \text { to } \\
4.355)\end{array}$ & $\begin{array}{c}0.696(-0.975 \text { to } \\
0.132)\end{array}$ \\
\hline \multirow{3}{*}{ CT Vol } & branching & $\begin{array}{c}-1.570(-2.671 \text { to }- \\
0.469)\end{array}$ & \multirow{3}{*}{$\begin{array}{c}1.375(1.160 \text { to } \\
1.589)\end{array}$} \\
\hline & encrusting & $\begin{array}{c}-1.638(-0.501 \text { to } \\
0.364)\end{array}$ & \\
\hline & massive & $\begin{array}{c}-0.579(0.610 \text { to } \\
1.373)\end{array}$ & \\
\hline
\end{tabular}


279 Photogrammetry provides fairly accurate estimates of the surface area and volume of coral 280 skeletons: $\mathrm{R}^{2}$ of best fit models range between 0.70 and 0.97 (Table 3 and Figure S2 and S3). 281 However, paired t-tests showed that the techniques for measuring 3D information, CT scanning 282 and photogrammetry, produced significantly different measurements from each other for 283 specimen volume $(\mathrm{t}=-2.549, \mathrm{df}=21, \mathrm{p}=0.019)$, TSA $(\mathrm{t}=2.91, \mathrm{df}=21, \mathrm{p}=0.008)$ and LSA $(\mathrm{t}$ $284=3.518, \mathrm{df}=21, \mathrm{p}=0.002)$. Photogrammetry generally underestimated TSA and overestimated 285 volume (Figure 5). Both photogrammetry and planar photography were less accurate at 286 predicting CT LSA than CT TSA. Model selection does not reveal bias associated to morphotype 287 for TSA and LSA, as the best model has constant scaling across morphotypes (Figure 5 A, B, 288 Table 3). In contrast, the best model for Vol does include different slopes and intercepts for 289 different morphotypes, as for massive colonies PH Vol is virtually identical to CT Vol, but for 290 both encrusting and branching colonies the PH Vol increasingly overestimates CT Vol as colony 291 sizes increase (Figure 5 C). 

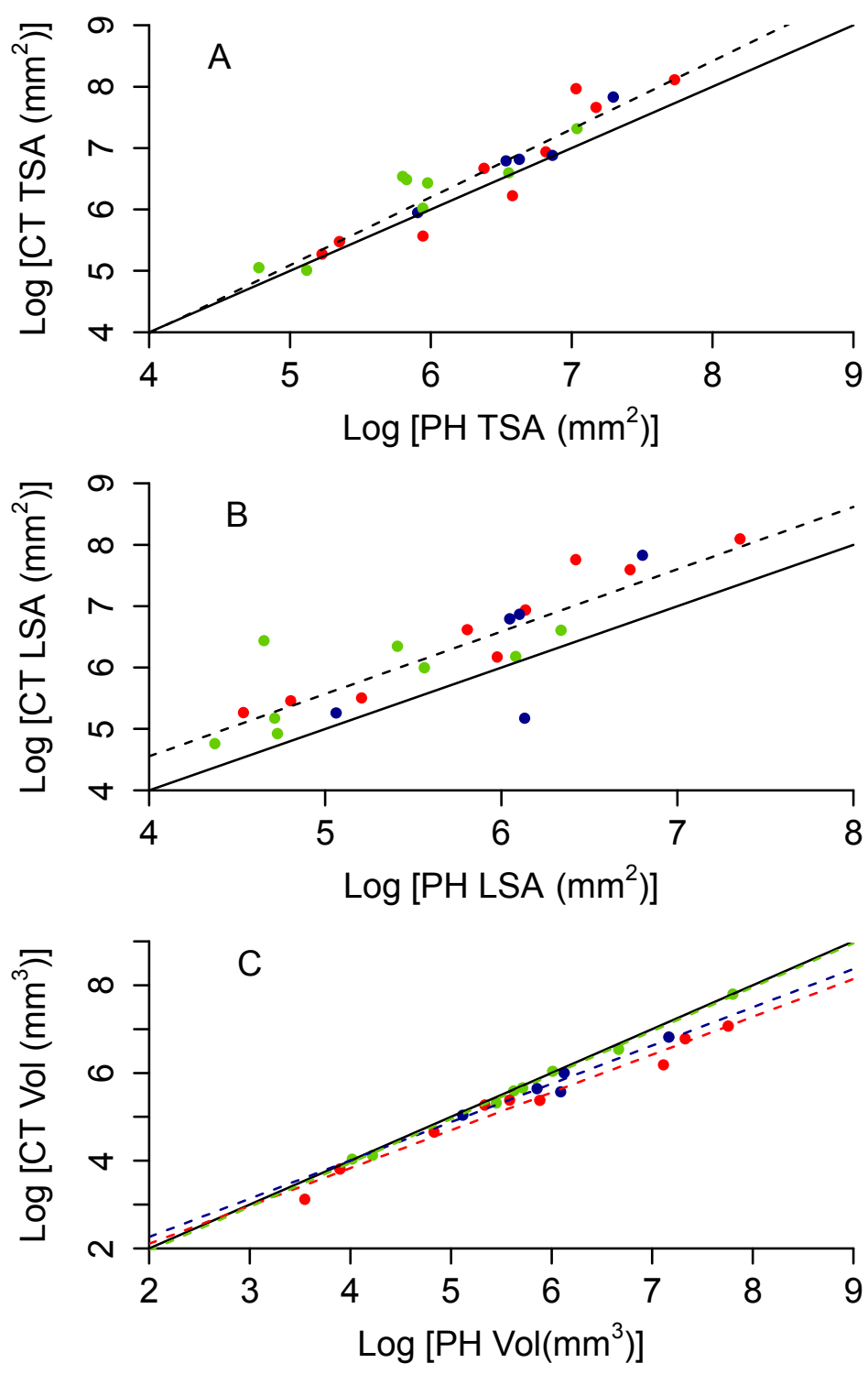

294 Figure 5. Relationship between CT and PH estimates of colony size. Red circles 295 represent branching colonies, blue encrusting and green massive. The solid lines 296 represent a model where the two metrics are identical. Dashed lines represent 297 predictions for the best model, with different colours for different morphotypes as 298 per the symbols when morphotypes differ in parameter estimates. 
301 Table 3: Predictive accuracy of Photogrammetry total and live surface area, and 302 volume (PH TSA, PH LSA, PH Vol, respectively) when used alone and with 303 morphotype to estimate total and live surface area and volume according to CT 304 scanning (CT TSA, CT LSA, CT Vol, respectively). Adjusted R², p value and 305 Akaike's Information Criterion (AIC) are given to 3 significant figures.

\begin{tabular}{|c|c|c|c|c|}
\hline Response & Predictor(s) & $\begin{array}{c}\text { Adjusted } \\
\mathbf{R}^{\mathbf{2}}\end{array}$ & $\mathbf{p}$ & AIC \\
\hline \multirow{3}{*}{ CT TSA } & PH TSA & 0.876 & $9.75 \times 10^{-11}$ & 16.319 \\
\hline & $\begin{array}{l}\text { PH TSA + } \\
\text { morphotype }\end{array}$ & 0.875 & $5.92 \times 10^{-9}$ & 18.074 \\
\hline & $\begin{array}{l}\text { PH TSA * } \\
\text { morphotype }\end{array}$ & 0.868 & $1.84 \times 10^{-7}$ & 20.686 \\
\hline \multirow{3}{*}{ CT LSA } & PH LSA & 0.702 & $3.64 \times 10^{-7}$ & 39.601 \\
\hline & $\begin{array}{l}\text { PH LSA + } \\
\text { morphotype }\end{array}$ & 0.692 & $3.55 \times 10^{-06}$ & 41.983 \\
\hline & $\begin{array}{l}\text { PH LSA * } \\
\text { morphotype }\end{array}$ & 0.690 & $3.31 \times 10^{-06}$ & 43.560 \\
\hline \multirow{3}{*}{ CT Vol } & $\mathrm{PH} \mathrm{Vol}$ & 0.955 & $1.02 \times 10^{-06}$ & 3.271 \\
\hline & $\begin{array}{l}\mathrm{PH} \mathrm{Vol} \mathrm{+} \\
\text { morphotype }\end{array}$ & 0.973 & $2.52 \times 10^{-10}$ & -6.432 \\
\hline & $\begin{array}{l}\text { PH Vol * } \\
\text { morphotype }\end{array}$ & 0.976 & $6.45 \times 10^{-9}$ & -7.847 \\
\hline
\end{tabular}




\section{Discussion}

308 We have improved our understanding of the relationship between 2D and 3D metrics of coral 309 colonies size and outlined an approach for converting between the two. For the size range 310 investigated, our results support the hypothesis that 3D metrics of size scale consistently with 311 planar area. Moreover, we demonstrated the potential for SfM to predict surface area and volume 312 of the CT scanner models (CT TSA/LSA and CT Vol). Together, our results suggest that: (i) 2D 313 data can be converted into more ecologically meaningful 3D metrics, such as colony surface area 314 and volume, when combined with information about colony morphotypes, and (ii) that a shift 315 towards $3 \mathrm{D}$ indicators in monitoring programs is possible, without losing comparability in the 316 process.

318 The measurements collected using SfM models were found to be significantly different from the results of the CT scans, but were nevertheless excellent predictors when combined with information about the morphotype of the colony. The differences observed are linked to the different resolutions of the two methods (much higher for CT scans, see appendix 2). Lower resolution 3D SfM models cause both the underestimation in surface area and the overestimation in volume. Our study adds to growing evidence that the previously prohibitive aspects of underwater photogrammetry are being overcome by technological improvements (Burns et al.,

325 2015a; Falkingham, 2012). Not only the possibility of applying this technique using open-source 326 software opens it up to a wider audience, but the costs of specific all-in-one SfM software is

327 decreasing and allowing greater control upon reconstruction parameter and resolution. The 328 application of photogrammetry to measuring reef topography (Burns et al., 2015b) combined 329 with our detailed modelling of individual coral colonies illustrates the wide range of potential 330 applications this technique can have in monitoring and studying coral reefs and their ecology at 331 different scales.

333 Quantifying size in 3D rather than 2D is time costly in both the field and the lab. We found that 334 SfM photogrammetry was easier to carry out when dealing with less complicated morphotypes, 335 which required less processing time and fewer photographs. SfM is particularly effective for 336 colonies with simpler structures and few occlusions, and it has been suggested that it could be a 337 valuable technique in areas with a high prevalence of hemispherical colonies, such as the 
338 Caribbean (Courtney et al., 2007). In contrast, calculating PL TSA/LSA took less time because it

339 required fewer photographs and less image processing. Although more complicated morphotypes

340 still required more processing than simple colony shapes, the difference in time and effort was

341 negligible compared to when using the photogrammetric approach. The labour-intensive nature

342 of measuring corals in $3 \mathrm{D}$, despite recent technological developments, does suggest that the

343 option of converting 2D measurements into 3D metrics may provide a useful alternative in cases

344 where conducting monitoring in $3 \mathrm{D}$ is not feasible due to the time or costs involved.

345 Additionally, SfM software improvements are making this approach faster, more efficient and 346 streamlined.

347

348 The most beneficial outcome from this study is that previously collected coral cover data may 349 converted into 3D metrics if morphotype was captured during collection (e.g., as categorical data 350 in line intercept transects or by re-analyzing video transects). This can help shifting towards 3D 351 without losing the possibility of comparisons with past measurements, overcoming in a smooth 352 way the "methodological inertia" that characterizes monitoring programs (Goatley and 353 Bellwood, 2011). We have produced empirical formulae that combine PL TSA/LSA and 354 morphotype categories to predict colony TSA/LSA or volume. Importantly, the predictive power 355 of these conversion models is similar to the estimates obtained through SfM. Our results indicate 356 the importance of recording the morphotype of a colony when conducting monitoring, as this 357 trait determines the relationship between some of the $2 \mathrm{D}$ and $3 \mathrm{D}$ metrics. Increasing the number 358 of specimens for each morphotype and widening the size spectra would further improve these 359 formulae, and it would be valuable also to expand them to additional morphotypes in the future.

361 Morphotype categories are not always clear-cut and the variability within groups supports the 362 need to move from discrete classifications of morphotypes towards individual level continuous 363 traits that measure colony shape. Moreover, our work suggests that surface area and volume, as 364 well as the ratios between these variables and planar area, are potential candidates as useful 365 traits. This shift in focus would also address the fact that corals can exhibit a high degree of 366 morphological plasticity within species (Todd, 2008), with colonies of the same species fulfilling 367 different categories of morphotype. This level of plasticity suggests that when our equations are 
368 used in the future they should be applied based on the morphotype observed in the field, rather

369 than one that is based on species identification and applied post hoc.

370

371 Improved understanding of the relationship between $2 \mathrm{D}$ and $3 \mathrm{D}$ parameters for different 372 morphotypes should contribute towards our grasp of the ecological role of different coral 373 morphotypes. We already know that morphotypes respond differently to disturbance (Madin \& 374 Connolly, 2006) and play different ecological roles (Alvarez-Filip et al., 2011). It has also been 375 suggested that examining the ratio of different coral morphotypes on reefs can give insight into 376 reef health (Edinger \& Risk, 2000). Our approach can provide a transition between traditional 377 methods and accurate 3D modelling, which will improve our understanding of the contribution 378 of different morphotypes to the services and functions provided by coral reefs. In addition to 379 applying our findings to future research, a significant benefit of using the equations developed 380 herein is that they can be applied to archived images and historical data sets. This will enable 381 data comparisons over as long a timescale as possible, minimising the "shifting baseline" effect 382 (Knowlton and Jackson, 2008).

383

\section{Conclusions}

385 In conclusion, coral colony surface area and volume can be predicted effectively from two 386 commonly collected variables: planar area (PL TSA) and morphotype. This quantitative development provides a stepping-stone that may enable better understanding and exploitation of historical data. Furthermore, SfM photogrammetry clearly contributes towards addressing the question of how best to measure corals because it is a widely accessible, non-invasive and cost effective method for making 3D measurements in-situ. This paper illustrates two specific areas for studying corals in ways that better capture changes amongst corals and the ecological accurate coral reef monitoring and conservation.

\section{Acknowledgements}

396 We thank the curator and staff at the Bell Pettigrew Museum for allowing us use of museum specimens, and the Behaviour and Biodiversity group at University of St Andrews for feedback. 
399

400

401

402

403

404

405

406

407

408

409

410

411

412

413

414

415

416

417

418

419

420

421

422

\section{References}

Agudo-Adriani EA, Cappelletto J, Cavada-Blanco F, Croquer A. 2016. Colony geometry and structural complexity of the endangered species Acropora cervicornis partly explains the structure of their associated fish assemblage. PeerJ 4:e1861. DOI: 10.7717/peerj.1861.

Airoldi L, Balata D, Beck MW. 2008. The Gray Zone: Relationships between habitat loss and marine diversity and their applications in conservation. Journal of Experimental Marine Biology and Ecology 366:8-15. DOI: 10.1016/j.jembe.2008.07.034.

Alvarez-Filip L, Côté IM, Gill JA, Watkinson AR, Dulvy NK. 2011. Region-wide temporal and spatial variation in Caribbean reef architecture: is coral cover the whole story? Global Change Biology 17:2470-2477. DOI: 10.1111/j.1365-2486.2010.02385.x.

Álvarez-Noriega M, Baird AH, Dornelas M, Madin JS, Cumbo VR, Connolly SR. 2016. Fecundity and the demographic strategies of coral morphologies. Ecology 97: 3485-3493.

Australian Institute of Marine Science, 2013. AIMS Coral Fact Sheets. Available at: http://coral.aims.gov.au/info/search.jsp.

Balmford A, Green RE, Jenkins M. 2003. Measuring the changing state of nature. Trends in Ecology and Evolution 18:326-330. DOI: 10.1016/S0169-5347(03)00067-3.

Booth DT, Cox SE, Meikle T, Zuuring HR. 2008. Ground-cover measurements: assessing correlation among aerial and ground-based methods. Environmental management 42:10911100. DOI: $10.1007 / \mathrm{s} 00267-008-9110-x$.

Bruno JF, Selig ER. 2007. Regional Decline of Coral Cover in the Indo-Pacific: Timing, Extent, and Subregional Comparisons. PLoS ONE 2:e711. DOI: 10.1371/journal.pone.0000711.

Bryson, M, Ferrari, R, Figueira, W, Pizarro, O, Madin, J, Williams, S, \& Byrne, M (2017). Characterization of measurement errors using structure-from-motion and photogrammetry to measure marine habitat structural complexity. Ecology and Evolution. 
423 Burns JHR, Delparte D, Gates RD, Takabayashi M. 2015. Integrating structure-from-motion

424 photogrammetry with geospatial software as a novel technique for quantifying 3D

425 ecological characteristics of coral reefs. PeerJ 3:e1077. DOI: 10.7717/peerj.1077.

426 Burns JHR, Delparte D, Kapono L, Belt M. 2016. Assessing the impact of acute disturbances on 427 the structure and composition of a coral community using innovative 3D reconstruction 428 techniques. Methods in Oceanography 15-16:49-59. DOI: 10.1016/j.mio.2016.04.001.

429 Burns JHR, Delparte D, Gates RD, Takabayashi M. 2015. Utilizing underwater three-

430

431

432

dimensional modeling to enhance ecological and biological studies of coral reefs. International Archives of the Photogrammetry, Remote Sensing and Spatial Information Sciences - ISPRS Archives 40:61-66. DOI: 10.5194/isprsarchives-XL-5-W5-61-2015.

433 434

435

436

437

438

439

440

441

442

443

444

445

446

Cignoni P, Corsini M, Ranzuglia G. 2008. Meshlab: an open-source 3d mesh processing system. Ercim news.

Cocito S, Sgorbini S, Peirano A, Valle M. 2003. 3-D reconstruction of biological objects using underwater video technique and image processing. Journal of Experimental Marine Biology and Ecology 297:57-70. DOI: 10.1016/S0022-0981(03)00369-1.

Courtney LA, Fisher WS, Raimondo S, Oliver LM, Davis WP. 2007. Estimating 3-dimensional colony surface area of field corals. Journal of Experimental Marine Biology and Ecology 351:234-242. DOI: 10.1016/j.jembe.2007.06.021.

Darling ES, Graham NAJ, Januchowski-Hartley FA, Nash KL, Pratchett MS, Wilson SK. 2017. Relationships between structural complexity, coral traits, and reef fish assemblages. Coral Reefs 36:561-575. DOI: 10.1007/s00338-017-1539-z.

Dornelas M, Madin JS, Baird AH, Connolly SR. 2017. Allometric growth in reef-building corals. Proceedings of the Royal Society B: Biological Sciences 284:20170053.

DOI: $10.1098 / \mathrm{rspb} .2017 .0053$. 
447 Edinger EN, Risk MJ. 2000. Reef classification by coral morphology predicts coral reef

448 conservation value. Biological Conservation 92:1-13. DOI: 10.1016/S0006-

449 3207(99)00067-1.

450 Fabricius KE, De'ath G, Noonan S, Uthicke S. 2014. Ecological effects of ocean acidification 451 and habitat complexity on reef-associated macroinvertebrate communities. Proceedings of 452 the Royal Society B: Biological Sciences 281:20132479. DOI: 10.1098/rspb.2013.2479.

453 Falkingham P. 2012. Acquisition of high resolution three-dimensional models using free, open454 source, photogrammetric software. Palaeontologia Electronica.

455 Ferrari R, Bryson M, Bridge T, Hustache J, Williams SB, Byrne M, Figueira W. 2016.

456 Quantifying the response of structural complexity and community composition to 457 environmental change in marine communities. Global Change Biology 22:1965-1975. DOI: $458 \quad 10.1111 / \mathrm{gcb} .13197$.

459 Ferrario F, Beck MW, Storlazzi CD, Micheli F, Shepard CC, Airoldi L. 2014. The effectiveness 460 of coral reefs for coastal hazard risk reduction and adaptation. Nature communications $461 \quad 5: 3794$. DOI: $10.1038 /$ ncomms4794.

462 Figueira W, Ferrari R, Weatherby E, Porter A, Hawes S, Byrne M. 2015. Accuracy and Precision 463 of Habitat Structural Complexity Metrics Derived from Underwater Photogrammetry. 464 Remote Sensing 7:16883-16900. DOI: 10.3390/rs71215859.

465 Furukawa Y, Curless B, Seitz SM, Szeliski R. 2010. Towards internet-scale multi-view stereo. 466 467 In Computer Vision and Pattern Recognition (CVPR), 2010 IEEE Conference on (pp. 14341441). IEEE.

468 469 470 471
Furukawa Y, Ponce J. 2010. Accurate, Dense, and Robust Multi-View Stereopsis. IEEE Transactions on Pattern Analysis and Machine Intelligence 32:1362-1376.

Gardner TA, Côté IM, Gill JA, Grant A, Watkinson AR. 2003. Long-term region-wide declines in Caribbean corals. Science (New York, N.Y.) 301:958-60. DOI: 10.1126/science.1086050. 
472 Goatley CHR, Bellwood DR. 2011. The roles of dimensionality, canopies and complexity in 473 ecosystem monitoring. PLoS ONE 6. DOI: 10.1371/journal.pone.0027307.

474 Graham NAJ, Wilson SK, Jennings S, Polunin NVC, Bijoux JP, Robinson J. 2006. Dynamic 475 fragility of oceanic coral reef ecosystems. Proceedings of the National Academy of Sciences 476 103:8425-8429. DOI: 10.1073/pnas.0600693103.

477 Gutierrez-Heredia L, Benzoni F, Murphy E, Reynaud EG. 2016. End to End Digitisation and 478 Analysis of Three-Dimensional Coral Models, from Communities to Corallites. PLoS ONE 479 11:e0149641. DOI: 10.1371/journal.pone.0149641.

480

481

482

483

484

485

486

487

488

489

490

491

492

493

494 495

Hata T, Madin JS, Cumbo VR, Denny M, Figueiredo J, Harii S, Thomas CJ, Baird AH. 2017. Coral larvae are poor swimmers and require fine-scale reef structure to settle. Scientific Reports :1-9. DOI: 10.1038/s41598-017-02402-y.

Hill J, Wilkinson C. 2004. Methods for Ecological Monitoring of Coral Reefs - A Resource for Managers.

Hoegh-Guldberg O. 1999. Climate change, coral bleaching and the future of the world's coral reefs. Marine and Freshwater Research 50:839-866.

Hughes TP, Baird AH, Bellwood DR, Card M, Connolly SR, Folke C, Grosberg R, HoeghGuldberg O, Jackson JBC, Kleypas J, Lough JM, Marshall P, Nyström M, Palumbi SR, Pandolfi JM, Rosen B, Roughgarden J. 2003. Climate Change, Human Impacts, and the Resilience of Coral Reefs. Science 301:929-933. DOI: 10.1126/science.1085046.

Jorstad A, Nigro B, Cali C, Wawrzyniak M, Fua P, Knott G. 2014. NeuroMorph: A Toolset for the Morphometric Analysis and Visualization of 3D Models Derived from Electron Microscopy Image Stacks. Neuroinformatics 13:83-92. DOI: 10.1007/s12021-014-9242-5.

Knowlton N, Jackson JBC. 2008. Shifting Baselines, Local Impacts, and Global Change on Coral Reefs. PLoS Biol 6:e54. DOI: 10.1371/journal.pbio.0060054. 
496 Laforsch C, Christoph E, Glaser C, Naumann M, Wild C, Niggl W. 2008. A precise and non497 destructive method to calculate the surface area in living scleractinian corals using X-ray 498 computed tomography and 3D modeling. Coral Reefs 27:811-820. DOI: 10.1007/s00338499 008-0405-4.

500 Lavy A, Eyal G, Neal B, Keren R, Loya Y, Ilan M. 2015. A quick, easy and non-intrusive 501 method for underwater volume and surface area evaluation of benthic organisms by 3D 502 computer modelling. Methods in Ecology and Evolution 6:521-531. DOI: 10.1111/2041$503 \quad 210 X .12331$.

504 Leujak W, Ormond RFG. 2007. Comparative accuracy and efficiency of six coral community 505

506 survey methods. Journal of Experimental Marine Biology and Ecology 351:168-187. DOI: 10.1016/j.jembe.2007.06.028.

507

508

509

510

511

512

513

514

515

516

517

518

519

520

Loya, Y. 1972. Community structure and species diversity of hermatypic corals at Eilat, Red Sea. Marine Biology, 13:2, 100-123

Madin JS, Baird AH, Dornelas M, Connolly SR. 2014. Mechanical vulnerability explains sizedependent mortality of reef corals. Ecology Letters 17:1008-1015. DOI: 10.1111/ele.12306.

Madin JS, Connolly SR. 2006. Ecological consequences of major hydrodynamic disturbances on coral reefs. Nature 444:477-480. DOI: 10.1038/nature05328.

McCarthy J, Benjamin J. 2014. Multi-image Photogrammetry for Underwater Archaeological Site Recording: An Accessible, Diver-Based Approach. Journal of Maritime Archaeology 9:95-114. DOI: 10.1007/s11457-014-9127-7.

Moberg F, Folke C. 1999. Ecological goods and services of coral reef ecosystems. Ecological Economics 29:215-233. DOI: 10.1016/S0921-8009(99)00009-9.

Naumann MS, Niggl W, Laforsch C, Glaser C, Wild C. 2009. Coral surface area quantificationevaluation of established techniques by comparison with computer tomography. Coral Reefs 28:109-117. DOI: 10.1007/s00338-008-0459-3. 
521 Noonan SHC, Jones GP, Pratchett MS. 2012. Coral size, health and structural complexity:

522 Effects on the ecology of a coral reef damselfish. Marine Ecology Progress Series 456:127-

523 137. DOI: $10.3354 /$ meps09687.

524 Pizarro O, Friedman A, Bryson M, Williams SB, Madin J. 2017. A simple, fast, and repeatable 525 survey method for underwater visual 3D benthic mapping and monitoring. Ecology and 526 Evolution 7:1770-1782. DOI: 10.1002/ece3.2701.

527 R Core Team. 2013. R: A language and environment for statistical computing. Available at: 528 http://www.r-project.org/.

529 Rasband W. 2014. ImageJ. Available at: http://imagej.nih.gov/ij/.

530 Raoult V, David PA, Dupont SF, Mathewson CP, O’Neill SJ, Powell NN, Williamson JE. 2016. 531 GoPros ${ }^{\mathrm{TM}}$ as an underwater photogrammetry tool for citizen science. PeerJ 4:e1960. DOI: $532 \quad 10.7717$ peerj.1960.

533 Raoult V, Reid-Anderson S, Ferri A, Williamson J. 2017. How Reliable Is Structure from 534 Motion (SfM) over Time and between Observers? A Case Study Using Coral Reef 535 Bommies. Remote Sensing 9:740. DOI: 10.3390/rs9070740.

536 Richardson LE, Graham NAJ, Hoey AS. 2017. Cross-scale habitat structure driven by coral 537 538 species composition on tropical reefs. Scientific Reports 7:7557. DOI: 10.1038/s41598-01708109-4.

539

Shuman CS, Ambrose RF. 2003. A Comparison of Remote Sensing and Ground-Based Methods for Monitoring Wetland Restoration Success. Restoration Ecology 11:325-333. DOI:

541 10.1046/j.1526-100X.2003.00182.x.

542 Storlazzi CD, Dartnell P, Hatcher GA, Gibbs AE. 2016. End of the chain? Rugosity and fine543 scale bathymetry from existing underwater digital imagery using structure-from-motion 544 (SfM) technology. Coral Reefs 35:889-894. DOI: 10.1007/s00338-016-1462-8. 
545 Sweatman H, Delean S, Syms C. 2011. Assessing loss of coral cover on Australia's Great Barrier 546 Reef over two decades, with implications for longer-term trends. Coral Reefs 30:521-531.

547 DOI: $10.1007 / \mathrm{s} 00338-010-0715-1$.

548 Todd PA. 2008. Morphological plasticity in scleractinian corals. Biological Reviews 83:315-337.

549 DOI: $10.1111 /$ j.1469-185X.2008.00045.x.

550 Veal CJ, Holmes G, Nunez M, Hoegh-Guldberg O, Osborn J. 2010. A comparative study of 551 methods for surface area and three-dimensional shape measurement of coral skeletons. 552 Limnology and Oceanography: Methods 8:241-253. DOI: 10.4319/1om.2010.8.241.

553 Vroom PS. 2011. "Coral Dominance”: A Dangerous Ecosystem Misnomer? Journal of Marine 554 Biology 2011:1-8. DOI: 10.1155/2011/164127.

555 Westoby MJ, Brasington J, Glasser NF, Hambrey MJ, Reynolds JM. 2012. "Structure-from556 Motion" photogrammetry: A low-cost, effective tool for geoscience applications.

557 Geomorphology 179:300-314.

558 Wu C. 2007. SiftGPU: A GPU implementation of scale invariant feature transform (SIFT). 559 Available: www.cs.unc.edu/ ccwu/siftgpu.

$560 \mathrm{Wu}$ C. 2011. VisualSFM: A visual structure from motion system. Available: 561 http://ccwu.me/vsfm/.

562 Wu C, Frahm JM, Pollefeys M. 2011. Repetition-based dense single-view reconstruction. 563 In Computer Vision and Pattern Recognition (CVPR), 2011 IEEE Conference on (pp. 564 3113-3120).

IEEE. 
